\title{
SCIENTIFIC SUBSTANTIATION OF THE METHODOLOGY OF PREPARATION OF QUINCE JAPANESE FOR ANALYSIS AND INVESTIGATION OF CONSUMER PROPERTIES OF THE PRODUCTS OF ITS RECYCLING
}

\author{
Dmytro Odarchenko \\ Department of commodity science, quality management and ecological safety \\ Kharkiv State University of Food Technology and Trade \\ 333 Klochkivska str., Kharkiv, Ukraine, 61051 \\ laboratory119@mail.ru \\ Andrey Odarchenko \\ Department of commodity science, quality management and ecological safety \\ Kharkiv State University of Food Technology and Trade \\ 333 Klochkivska str., Kharkiv, Ukraine, 61051 \\ 3494545@ukr.net \\ Olena Lisnichenko \\ Department of commodity science, quality management and ecological safety \\ Kharkiv State University of Food Technology and Trade \\ 333 Klochkivska str., Kharkiv, Ukraine, 61051 \\ kdkethduht@ukr.net \\ Kateryna Spodar \\ Department of commodity science, quality management and ecological safety \\ Kharkiv State University of Food Technology and Trade \\ 333 Klochkivska str., Kharkiv, Ukraine, 61051 \\ katrin-0503@ukr.net
}

\begin{abstract}
The aim of the study is a scientific substantiation of the methodology of quince Japanese for analyzing and investigating consumer properties of its recycling products. The new way of sample preparation allows to reduce costs for estimation of the raw material quality. Obtained semi-products give a possibility to widen the assortment of frozen products, based on domestic raw materials.

Fruits of quince Japanese, planted in the Poltava region, Ukraine, were chosen as a research object. For getting a representing sample, quince specimens were subjected to the offered sample preparation. It included inspection, processing and further cyclic freezing and centrifuging. As a result of the threefold cycle of freezing-centrifuging, solid and liquid phases were obtained.

The obtained liquid part of quince Japanese is a homogenous liquid, without suspended particles, with a brightly expressed taste and smell, not stratified at storage. These changes are explained by redistribution of dry substances and moisture in studied samples.

As a result of cyclic freezing-centrifuging of the research object, two new semi-products were obtained - solid and liquid phases.

Within the scientific study there were determined organoleptic parameters of the obtained semi-products before freezing and after 270 days of low-temperature storage. The consistence, taste, smell and color of products are ones of their main consumption properties.

According to the results of point estimation of organoleptic properties of the obtained semi-products, it has been established, that during 270 days of low-temperature storage these parameters didn't change and stayed at the high level.

The studies demonstrated freezing advantages in the aspect of reaching high organoleptic parameters of products after freezing and defrost that provides high-quality products in the process of low-temperature storage.

Keywords: quince Japanese, frozen semi-product, sample preparation, low-temperature storage of quince.
\end{abstract}




\section{Introduction}

Preparation of the research subject to the analysis is an important part of the analysis in the whole. Properties of food products are determined by their chemical composition, taking into account not only main components, but also admixtures [1].

Most food products are complicated chemical compositions, heterogenic by structure and reactive, similar to biological materials of their origin. This form would allow to construct a certain behavior model of a food product or process (or complex of processes, involved in degradation of products at storage, their use and consumption).

At the same time properties of raw materials depend on distribution of admixtures or components by the whole volume $[2,3]$. That is why the specificity of any method for quality parameters determination is in fact that a reagent, used in it, has certain sensitivity to a substance that conditions just this parameter.

Such substances are in the soluble or insoluble condition, so, can be concentrated in the solid or liquid part of studied raw materials. Heterogenic systems have different stability degrees and can be usually disintegrated under the influence of mechanical forces [4-6]. At that one phase is solid and is called dispersive, and the other one is fine distributed in the first one - disperse phase.

Different methods, such as comminution, dissolution and other are traditionally applied in chemical analysis for obtaining a homogenous substance [7].

At that associated substances that influence the objectivity of the analysis may appear in a studied sample [8]. So, at operations for sample preparation it is necessary to be aimed at obtaining the homogenous system by disintegrating a studied raw material in two phases: solid and liquid.

Preparation of studied samples for the analysis is necessary for transforming all components of a sample in a form, necessary for conducting it. For this aim there are used all methods, applied in chemical analysis: comminution of solid specimens, dissolution, processing by different chemical reagents, heating [9].

For determining the quality of the research objects and their component composition, it was offered to introduce an operation of preliminary preparation, in which result the studied raw material must look as a homogenous system at the expanse of its disintegration in liquid and solid phases. For separating a liquid phase from a solid one, different methods may be used, such as filtration, pressing, centrifuging and sedimentation [10].

The method of raw material separation is chosen, based on the dispersion condition of a substance and its physical properties. At that methods, characterized by the high kinetics of system separation using additional forces, for example, centrifugal ones, are considered as more effective. At such conditions centrifuging, rather often used for processes of centrifugal sedimentation and filtration, is the most optimal method.

Mixture separation by the centrifuging method is realized by the sedimentation principle, but the centrifugal force and not gravity one is crucial.

The physical essence of the sedimentation process under the effect of the centrifugal force is that particles of the rotating flow are affected by the centrifugal force, directs it to the periphery from the center with a speed, equal to sedimentation one. At that the sediment is compressed, and moisture is isolated.

As a result two phases form: liquid and solid one (sediment). The obtained systems are not at once homogenous: the liquid phase contains particles of a solid substance, and the sediment is characterized by a rather high humidity.

The character of separation of any product in phases depends on the ability of solid phase substances to retain moisture. That is why it was decided to freeze the phases of food products additionally for breaking these connections and fuller separation of the liquid phase.

The main physical process at freezing of raw materials is transformation of cellular juice in ice that results in partial destruction of cellular tunics and leak of cellular juice at defrost.

Based on the aforesaid, the aim of the work is a scientific substantiation of the methodology of quince Japanese for analyzing and investigating consumer properties of its recycling products that allows, in the first turn, to reduce costs for estimation of the raw material quality and also to obtain new semi-products to widen the assortment of frozen products. 


\section{Materials and Methods}

Fruits of quince Japanese, planted in the Poltava region, Ukraine, were chosen as a research object. They were harvested in the stage of complete ripeness.

The scheme of samples obtaining is presented on Fig. 1.

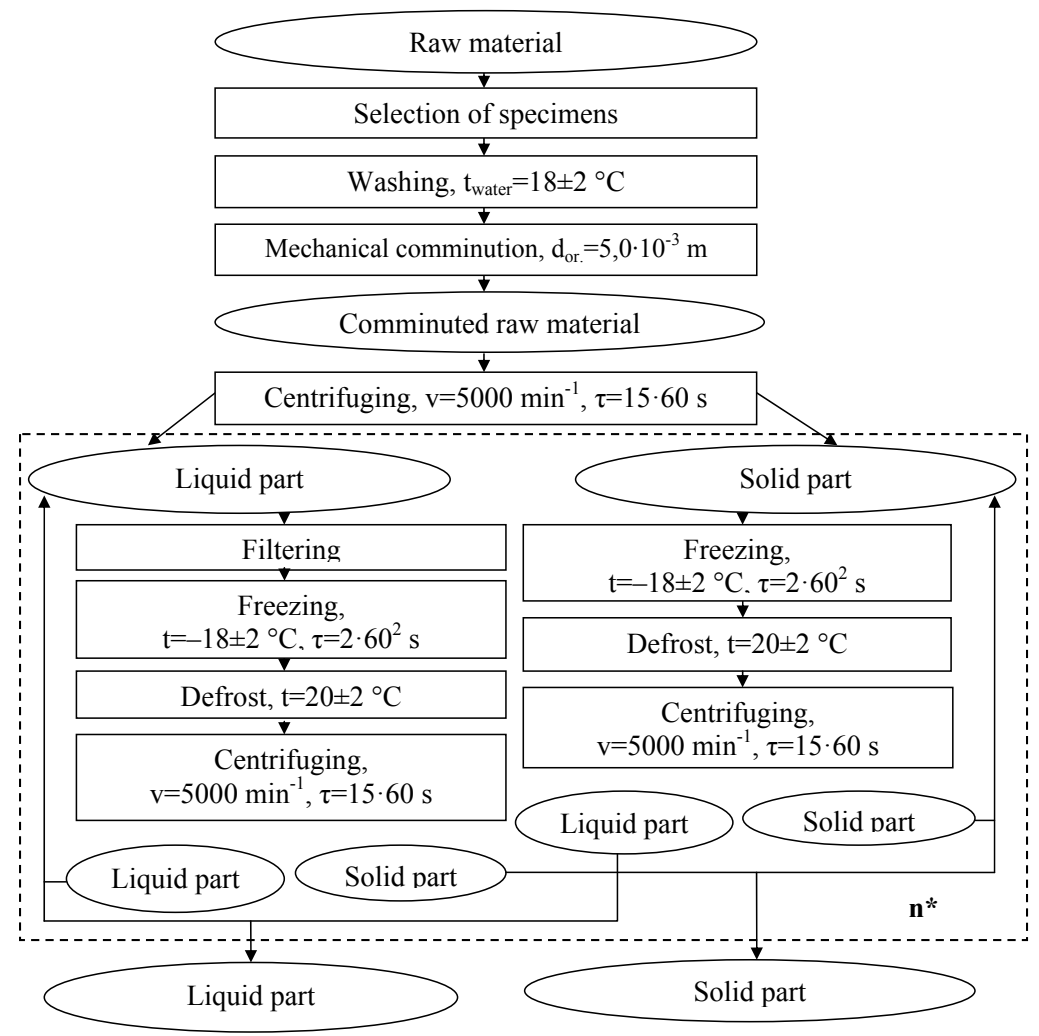

Fig. 1. Scheme of samples obtaining: $n^{*}$ - number of cycles

The general methodology of samples preparation of the raw material for conducting further studies provides the following stages:

1. Comminution of the raw material into the correspondent dispersion.

2. Centrifuging of the comminuted mixture with the following parameters of the process: speed 5000 turn/min., during $15 \mathrm{~min}$. At centrifuging the isolated liquid is added to the total volume of the liquid phase, and the sediment, formed at centrifuging of the liquid phase, is added to the total mass of the solid phase.

3. Freezing of the solid and liquid phases, obtained after centrifuging, is realized separately in a hermetically sealed container at temperature $-18 \pm 2{ }^{\circ} \mathrm{C}$ during 3 hours.

4. Defrost of the liquid and solid phases takes place at the room temperature to the complete melting of ice in the mixture.

5. Repeated centrifuging is realized by the aforesaid parameters.

The number of cycles is determined by the share of moisture in the solid phase of the raw material. After reaching the set value of this parameter, the mixture is stopped to be disintegrated. The threefold cyclic freezing-centrifuging was used in this study.

The studies were realized in the laboratory of medical-biological problems of the technology of food products in the Kharkiv State University of food technology and trade in Ukraine.

\section{Results}

As a result of the threefold cyclic freezing-centrifuging of fresh fruits of quince Japanese, the experimental specimens were obtained - liquid and solid parts (Fig. 2, 3). 


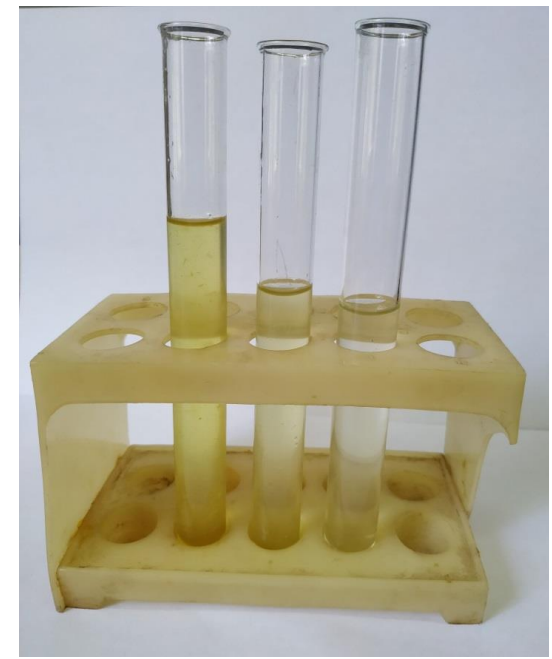

Fig. 2. Recycling products of quince Japanese (liquid part) after cyclic freezing-centrifuging (from the left to the right - after the first cycle, after the second cycle, after the third cycle)

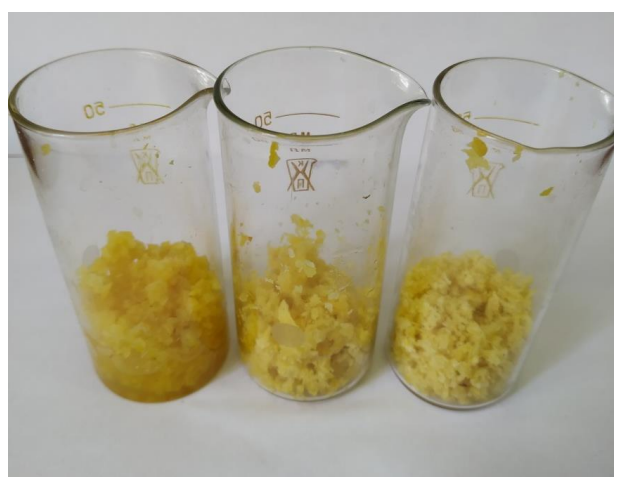

Fig. 3. Recycling products of quince Japanese (solid part) after cyclic freezing-centrifuging (from the left to the right - after the first cycle, after the second cycle, after the third cycle)

The solid part of quince Japanese after the third cycle of freezing-centrifuging is a liquid without suspended particles. These changes are explained by redistribution of dry substances and moisture in the studied specimens.

After the third cycle of freezing-centrifuging there were obtained two new semi-products that, in their turn, widened the assortment of frozen ones. That is why there were studied organoleptic parameters of the obtained semi-products before freezing and after 270 days of low-temperature storage that are ones of main consumption properties of food products. It is inexpedient to study organoleptic properties of recycling products of quince Japanese in the process of low-temperature storage for more than 270 , because new quince fruits are harvested during the following three months.

According to requirements of SSU 6029:2008 "Fruit and berry fast-frozen semi-products (comminuted and puree-like)" such organoleptic parameters as a consistence, color, taste and smell of products are standardized.

The estimation was realized by the gustatory commission of the department of commodity research, management of quality and ecological safety of food products of Kharkiv State University of food technology and trade in Ukraine, consisted of 10 persons. Recycling products of quince Japanese were estimated by the point system. 5-point system was used for point quality estimation, it was presented in gustatory documents, where 5 - the best index, 1 - the worst one.

Each parameter (consistence, color, taste, smell) had 5 quality degrees, expressed in points (Table 1). 
Table 1

Point estimation of the quality of semi-products

\begin{tabular}{|c|c|c|}
\hline Parameters & Quality characteristic & Points \\
\hline & Homogenous, even & 5 \\
\hline \multirow[t]{3}{*}{ Consistence } & Insufficiently homogenous, with unessential stratification of solid and liquid parts & $3-4$ \\
\hline & Heterogenic with complete stratification of particles & $1-2$ \\
\hline & Bright, inherent to the initial raw material & 5 \\
\hline \multirow[t]{3}{*}{ Color } & Insufficiently bright, a bit doesn't correspond to the color of the initial raw material & $3-4$ \\
\hline & Not typical for this type of raw material & $1-2$ \\
\hline & Brightly expressed, pleasant, harmonic & 5 \\
\hline \multirow[t]{3}{*}{ Taste } & Pleasant, corresponds to this type of raw material, without side smacks & $3-4$ \\
\hline & Not expressed & $1-2$ \\
\hline & Pleasant, brightly expressed, without side smells & 5 \\
\hline \multirow[t]{2}{*}{ Smell } & Weakly expressed, without side smells & $3-4$ \\
\hline & Not expressed & $1-2$ \\
\hline
\end{tabular}

The results of the organoleptic estimation of the obtained semi-products are given in Tables 2, 3.

Table 2

Change of the organoleptic parameters of the liquid part of quince Japanese, obtained after the 3 cycle of freezing-centrifuging

\begin{tabular}{ccc}
\hline Parameters & Before freezing & After refrigerator storage during 270 days \\
\hline Consistence & Homogenous, even & Homogenous, even, without stratification \\
Color & Even by the whole mass & Even, inherent to the initial raw material \\
Taste & Pleasant, expressed, harmonic & Pleasant, corresponds to this type of raw material \\
Smell & Pleasant, brightly expressed, without side smells & Pleasant, without side smells
\end{tabular}

Table 3

Change of the organoleptic parameters of the solid part of quince Japanese, obtained after the 3 cycle of freezing-centrifuging

\begin{tabular}{|c|c|c|}
\hline Parameters & Before freezing & After refrigerator storage during 270 days \\
\hline Consistence & Homogenous without cellular juice separation & Homogenous, evenly distributed \\
\hline Color & $\begin{array}{c}\text { Even by the whole mass, inherent to } \\
\text { the initial raw material }\end{array}$ & $\begin{array}{c}\text { Even by the whole mass, inherent to } \\
\text { the initial raw material }\end{array}$ \\
\hline Taste & Pleasant, expressed, harmonic & Expressed, pleasant, without side smacks \\
\hline Smell & Pleasant, brightly expressed, without side smells & Pleasant, without side smells \\
\hline
\end{tabular}

The results of the organoleptic estimation of the semi-product demonstrated that the product is characterized by the high quality. Its consistence both before and after freezing was homogenous with evenly distributed finely comminuted flesh. The color after freezing remained bright, even along the whole mass. The taste and smell are brightly expressed, pleasant and harmonic. 
For realizing the offered method of sample preparation, a high- qualified staff and expensive equipment are not needed that gives a possibility to reduce costs for the analysis of the vegetable raw materials.

As a result of the offered method of raw materials preparation for the study, there were obtained two new products that widened the assortment of frozen semi-products, based on vegetable domestic raw materials.

\section{Conclusions}

Comminution of vegetable raw materials with their further threefold freezing-centrifuging allows to obtain the representing part of a specimen in the whole. This method may be adapted to any type of raw materials that, in its turn, doesn't need a high-qualified staff and expensive equipment. Such sample preparation gives a possibility to reduce costs at estimating the raw material quality.

It has been established, that the obtained recycling products of quince Japanese have the high organoleptic properties.

In the process of low-temperature storage during 270 days at temperature $-18 \pm 2{ }^{\circ} \mathrm{C}$ there weren't detected any changes of the main organoleptic parameters of recycling products of quince Japanese, such as a consistence, taste, smell and color. It testifies to the positive influence of low temperatures on the quality of the obtained semi-products.

The described technology of sample preparation gives a possibility to widen the assortment of frozen products, to increase their storage term and to preserve healthy properties and food qualities. The use of frozen semi-products at trade enterprises, in hotel-restaurant business and everyday life favors better organization of the staff's work, economy of production resources.

\section{References}

[1] David, I. G., Litescu, S. C., Popa, D. E., Buleandra, M., Iordache, L., Albu, C. et. al. (2018). Voltammetric analysis of naringenin at a disposable pencil graphite electrode - application to polyphenol content determination in citrus juice. Analytical Methods, 10 (48), 5763-5772. doi: https://doi.org/10.1039/c8ay02281j

[2] Farajzadeh, M. A., Sadeghi Alavian, A., Sattari Dabbagh, M. (2018). Application of vortex-assisted liquid-liquid microextraction based on solidification of floating organic droplets for determination of some pesticides in fruit juice samples. Analytical Methods, 10 (48), 5842-5850. doi: https://doi.org/10.1039/c8ay01766b

[3] Serdyuk, M., Stepanenko, D., Baiberova, S., Gaprindashvili, N., Kulik, A. (2016). Substantiaton of selecting the method of pre-cooling of fruits. Eastern-European Journal of Enterprise Technologies, 4 (11 (82)), 62-68. doi: https://doi.org/10.15587/1729-4061.2016.76235

[4] Cheng, H. N., Neiss, T. G. (2012). Solution NMR Spectroscopy of Food Polysaccharides. Polymer Reviews, 52 (2), 81-114. doi: https://doi.org/10.1080/15583724.2012.668154

[5] Spyros, A., Dais, P. (2012). NMR spectroscopy in food analysis. RSC food analysis monographs, 343. doi: https://doi.org/10.1039/9781849735339

[6] Van Duynhoven, J., Voda, A., Witek, M., Van As, H. (2010). Time-Domain NMR Applied to Food Products. Annual Reports on NMR Spectroscopy, 145-197. doi: https://doi.org/10.1016/s00664103(10)69003-5

[7] Monakhova, Y. B., Schütz, B., Schäfer, H., Spraul, M., Kuballa, T., Hahn, H., Lachenmeier, D. W. (2013). Validation studies for multicomponent quantitative NMR analysis: the example of apple fruit juice. Accreditation and Quality Assurance, 19 (1), 17-29. doi: https://doi.org/10.1007/s00769-013-1026-3

[8] Zhang, X., Zhao, Y., Cui, X., Wang, X., Shen, H., Chen, Z. et. al. (2018). Application and enantiomeric residue determination of diniconazole in tea and grape and apple by supercritical fluid chromatography coupled with quadrupole-time-of-flight mass spectrometry. Journal of Chromatography A, 1581-1582, 144-155. doi: https://doi.org/10.1016/j.chroma.2018.10.051

[9] Vojtylov, V. V., Petrov, M. P., Spartakov, A. A., Trusov, A. A. (2013). The effect of the size of particles on optical and electrooptical properties of colloids. Optics and Spectroscopy, 114 (4), 630-638. doi: https://doi.org/10.1134/s0030400x13030272

[10] Klemeshev, S. A., Petrov, M. P., Trusov, A. A., Voitylov, A. V. (2010). Electrooptical effects in colloid systems subjected to short pulses of strong electric field. Journal of Physics: Condensed Matter, 22 (49), 494106. doi: https://doi.org/10.1088/0953-8984/22/49/494106 